\title{
INTELLIGENCE CYCLE AS PART OF EFFECTIVE RISK ANALYSIS UNDER INTEGRATED BORDER MANAGEMENT
}

\author{
Jekaterina Livdāne ${ }^{1}$, Iluta Arbidāne ${ }^{2}$ \\ ${ }^{1}$ Master of social sciences, Lecturer of Border Guard and Immigration Service Subjects \\ Department of the State Border Guard College, \\ e-mail: jekaterina.livdane@rs.gov.lv, Rēzekne, Latvia \\ ${ }^{2}$ Professor, Dr.oec., Rezekne Academy of Technologies, e-mail: iluta.arbidane@rta.lv, \\ Rēzekne, Latvia
}

\begin{abstract}
The aim is to present common approach of processing of information as one of the main aspects for qualitative risk analysis, including all three components - threat, vulnerability and impact, in all levels: strategic, operational and tactical. The theoretical methodology is based on guidelines of common integrated risk analysis model (CIRAM), implemented in Schengen member states (MS) as a part of integrated border management (IBM). Based on the main task - to view particular legal bases and using historical research, analytical and descriptive methods, the legal bases of IBM in the field of risk analysis was explained, at first. Special attention was paid for description of each step of intelligent cycle, because only scrupulous following of methodology guaranteed the high quality of the product in situations when analytical units have huge amount of data from different sources every day. Different kinds of risk analysis (annual, quarterly, monthly, weekly or targeted for specific measures) are performed by European Border and Coast Guard (EBCG) and MS using the CIRAM methodology. Huge data flows should be managed in a structured way. The knowledge and practical implementation of CIRAM has a positive impact on overall internal security in the area of free movement. For this purpose, the amount of trained border guards was analysed.
\end{abstract}

Keywords: data management, information, intelligent cycle, risk analysis, sources.

\section{Effective risk analysis - key stone of integrated border management}

Historically, when the area of free movement (Schengen zone) was created, the issue of risk analysis in this formulation was not of paramount importance. An integrated approach was taken to protect the common borders of the community, examining all interrelated areas and identifying possible strengths and weaknesses.

With a generalization of the best practices and recommendations for effective border control (Schengen Catalogue, 2002), appropriate terminology was introduced into use - "risk analysis", "risk level", "operational level", "tactical level".

"Activities at the external borders" (Schengen Catalogue, 2002) it has been determined that the main area of the overall border strategy is functioning border management, consisting of border checks and border 
surveillance based on risk analysis". It should be noted that at this stage the implementation of risk analysis was advisory in nature.

In 2004, the Frontex Agency was created by the European Parliament and Council regulation, among other tasks, the task of conducting a risk analysis was delegated to the Agency.

Based on the CIRAM model, which was developed in 2003, the Agency was obliged to carry out a risk analysis in order to provide the Commission and the MS with adequate information about the situation near the external borders. The purpose of these measures was to take appropriate measures or eliminate identified threats and risks to improve IBM. That is, risk analysis has become mandatory for Frontex. But not for MS at this moment.

In turn, the Schengen Border Code as the part of IBM, in its first edition (2006), determined that border control includes not only checks at the border control points (BCP) and surveillance between BCPs, but also an analysis of the risk to internal security and an analysis of threats that could cause damage security of external borders.

Developing the IBM system of protecting external borders, in 2013 the regulations of the EUROSUR system were approved, the main purpose of which was the exchange of information and operational cooperation between countries, the vision of the overall picture in real time.

The migration crisis in 2015 revealed the need for more targeted measures than before. The tasks and responsibilities of the Agency were expanded with the approval of the new Frontex regulation in 2016, which secured 11 elements of IBM at the legislative level.

Among these 11 elements, designed to manage migration processes, as well as to ensure the security of external borders and internal security, a risk analysis according to the CIRAM model was developed into a separate element. The need for a vulnerability assessment was enshrined in law.

Also, article 4 of the updated Frontex Regulation defined the principle of cooperation with third countries, indicating that cooperation primarily focuses on neighbouring countries and those countries that, through risk analysis, are identified as countries of origin of illegal migration or transit countries on their way to Europe.

In turn, Article 11 (Regulation 1624/2016, 2016) provided for monitoring migration flows within the Schengen area and beyond in order to maintain preparedness for probable challenges in the field of illegal migration. Thus, for these purposes, the ongoing risk analysis according to the CIRAM model has become mandatory for MS.

The introduction of a systematic check of all persons crossing the border in 2017 , designed to establish that the person is not considered a threat to the public order, internal security, public health or international relations of any of the MS, including in consultation with the Schengen 
Information System and others relevant Union databases, emphasized the importance of analysing and assessing likely threats to internal security. (EBCG Consolidates Annual activity report, 2019).

In November 2019, the updated regulation on the European Border and Coast Guard came into force, which combines the regulations of the Eurosur system and the regulations of the Agency (Regulation 1864/2019, 2019).

As indicated by the first objective of Frontex, the Agency is responsible for monitoring migration flows and risk analysis for all aspects of IBM. The duty also includes conducting a vulnerability assessment, including assessing the readiness of MS to avert a threat and solve probable problems at external borders.

Thus, summarizing the above, it can be noted that today the legal basis for risk analysis performed by the EBCG and MS are two regulations - the Schengen Borders Code and the regulations of the European Border and Coast Guard, operates within IBM.

\section{Information management - quality approach}

With so many MS and other partners involved in operations, and the quantity of data that needs to be sorted and analysed, information management is an important aspect of Frontex's work. With over 42,000 $\mathrm{km}$ of coastline, almost 9,000 $\mathrm{km}$ of land borders and around 300 international airports, Europe sees around 500 million border crossings a year. The job of managing the flow of legal and illegal migration requires a clear picture of the current situation at all the EU's external borders - from airports as well as from the EU's other approximately 1800 Border Crossing Points both on land and at sea ports (EBCG, 2019).

The main question in the field of risk analysis is - how to process this huge amount of necessary data? The core stone is CIRAM - systematic and structured approach. The abbreviation CIRAM describes its meaning (CIRAM guidelines, 2012):

- common - refers to the concept of a methodology developed by the MS and EBCG for joint application at the national and European levels;

- integrated - refers to the goal of EBCG to promote IBM, while ensuring external border control at a high level;

- model - refers to an analysis system that ensures the use of common terminology and rules from all MS;

- risk analysis - refers to the systematic assessment of risk elements in order to inform persons responsible for the decision-making.

The risk analysis system is a systematic information management, with the help of which it becomes possible to identify and assess the 
current or potential threat, vulnerability and impact in the field of border security. Information management is based to intelligent cycle (Fig. 1).

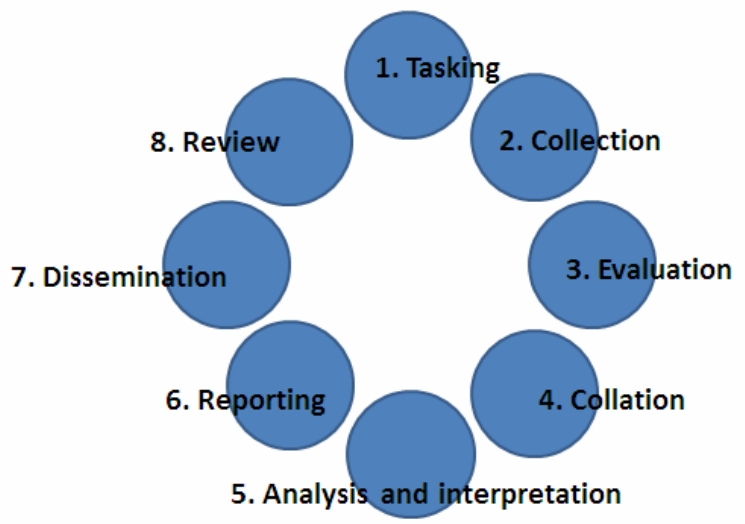

Figure 1. Intelligence cycle (CIRAM guidelines, 2012)

The cycle consists of 8 consecutive steps. The key importance of the methodology is the observance of the order of all steps, as well as quality work at each step.

The step number one is tasking, whether it is the preparation of a periodic product (for example, an annual risk analysis) or targeted action to analyse a specific phenomenon (for example, illegal entry into the EU at a certain border control point). In order to get answers to the questions posed, the terms of reference (TOR) are being developed:

- the main goal of product developed by collecting and analysing information should be defined;

- the initial picture on this problem, the availability of historical data should be stated - what is required (for example, to inform about the trend or is its proactive information that needs an immediate response);

- a certain framework (for example, the admissibility of consultations with experts, the time period for analysis, required methodology; type of document, language, needs for classification of access to the final product);

- a phased plan for the implementation of the task is also being developed - who (individually or as a team/ possessors of certain skills), what/ when and how performs a task, with the definition of deadlines.

Why is this initial step so important? Using the TOR covers all important aspects of the request. The requirements that are put forward to the analytical product are clearly defined. Also, there is absolute clarity in the matter of the necessary human and time resources for conducting a 
qualitative analysis. The CIRAM model advocates with the installation - "if something went wrong, this indicates gaps in the tasking".

The step number two is collection. The collection of information as part of the intelligent cycle is a planned activity. Of course, this does not exclude the routine process for previously defined tasks. Information gathering in accordance with the task is carried out on all three risk components and covers 4 levels of IBM (Fig. 2).

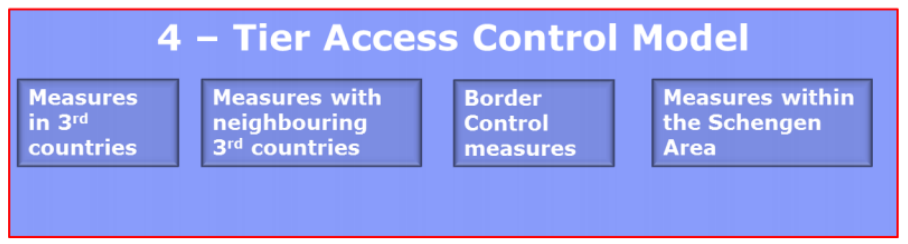

Figure 2. Integrated Border Management basis, 4-tier model (European Commission, 2017)

An important component of the collection is the direct relationship between quality analysis and access to meaningful, sufficient information and sources. At this step, particular importance is given to the sources of information, the information itself and the timeframe for obtaining the necessary information.

The step number three is evaluation. Collected information is evaluated on its suitability to the task, as well as assessing the reliability of sources and validitiy of information. For sources of information gradation from A to $\mathrm{X}$ is used, where the value $\mathrm{A}$ is assigned to the source in the reliability and competence of which there is no doubt. And further - by decreasing gradation to $\mathrm{X}$, when it is not possible to assess the reliability of the source (for example, a new established regional newspaper). The most reliable sources are databases, information systems, Europol data, a system for recording incidents from joint operations of Frontex.

The information itself is estimated in a similar way, using a gradation from 1 to 4 . Thus, 1 - the validity of the information is not questioned (even if it is obtained from a dubious source, but confirmed by a reliable source). Index 4 is assigned to information from a previously unknown source, and there is no way to otherwise confirm its validity (CIRAM guidelines, 2012).

The step number four is collation. After evaluating the sources and information, it is filtered - systematized for future use. Perhaps at this step it becomes clear that the information itself is valuable, but does not apply to a given task. Such information may be used in the future for other purposes. 
The step number five is analysis and interpretation. This step is the culmination of mental processing of information. Here the whole picture becomes visible, when the assumptions put forward earlier are confirmed or refuted by reasoned judgments, thus being converted into conclusions. The main question at this stage is the question "why?", Which refers to the validity of the conclusions. In order to systematize the work of the analyst on all three risk components, the TVI / IDM matrix is used (Fig. 3).

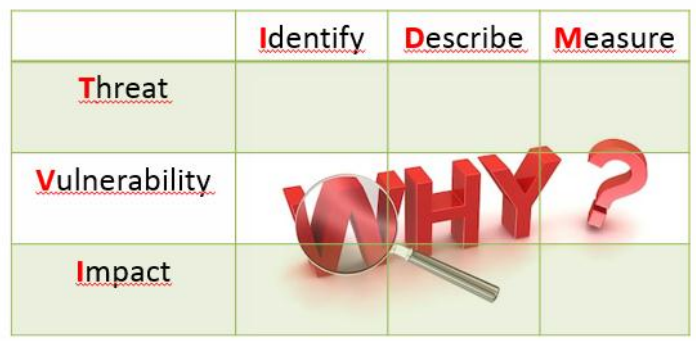

Figure 3. Risk matrix (Author created, CIRAM analysts learning course materials, 2019)

The step number six is reporting - compilation or writing of a report. For this process, it is extremely important to refer to the initial requirements that were displayed at the first step when setting the task. It is also here that recommendations are made, if any, were requested at the first step.

The step number seven is dissemination. Any analytical product is classified in accordance with national requirements, registered in the manner prescribed by the institution. Also, at this step, feedback is important to all who was involved in the creation of product - local and regional levels or partners, from whom the necessary information was received at the initial steps. If it is not possible to distribute the analytical product due to its classification, it is necessary to compile a publicly available version of the document that does not contain a description of the vulnerability, as well as recommendations.

The step number eight is review. At the final step, an assessment of the effectiveness of the product takes place - is it possible to achieve the goal with its help (for example, if this is a tactical warning, is it possible to identify identical cases) and an assessment of the effectiveness of the work done is whether all the necessary actions were carried out in accordance with the requirements, how was the collection and evaluation of information, etc. 
The advantages of using this methodology are the organization and systematization of the process, its structure, lack of randomness. Effective distribution of resources plays a very important role in conditions when they are limited by the number of responsible persons involved in the process or by performing other tasks. An undoubted advantage is the observance of time limits and the recognized quality of the analytical product developed in compliance with this methodology.

At the State Border Guard of Latvia the Frontex CIRAM learnig course are graduated by 3 officers, who are involved in study process delivering for local level officers. The updated qualification increasing program for local level officers from structural units, provided by State Border Guard College, was implemented from december, 2018.

27 border guards (41\%) who in their daily duties are responsible for risk analysis, are trained at the begining of 2020 .

\section{Conclusions}

Thus, the core of the analytical process are analytical actions, as a result of which the transformation of information into an analytical product occurs.

Analytical actions, namely following certain rules for processing of information, ensure the quality of the products being created. Using common terminology and methodology allows all MS to reach better understanding, speak the same language, and communicate in the field of risk analysis. It is also a good platform for measures of cooperation between the structures that are involved in the IBM process.

The global goal of risk analysis is to identify potential threats before they arise in order to plan the necessary actions to reduce or prevent the likely negative impact.

An integrated approach to risk analysis provides the opportunity for effective cooperation between law enforcement agencies involved in protecting the external borders of the EU. The basic principle of the information processing remains unchanged - successive regulated actions aimed at making decisions! Continuing the training process at the State Border Guard College of Latvia, it can be expected, that at the 2022, everyone border guard, who is responsible for the risk analysis at the local level, will be trained.

\section{References}

1. European Border and Coast Guard (2019) Consolidated Annual Activity Report Nr.5865. Retrieved July 11, 2020, from https://www.europarl.europa.eu/cmsdata/185405/CAAR\%202018.pdf 
2. European Border and Coast Guard (2019). Information Management. Retrieved July 11, 2020, https://frontex.europa.eu/intelligence/information-management/

3. EUROPEAN COMMISSION (2017). European Integrated Border Management Strategy. Meeting of the Expert Group "Management of the External Borders". Retrieved July 11, 2020, from https://ec.europa.eu/transparency/regexpert/index.cfm?do=groupDetail.groupDe tailDoc\&id=33415\&no=7

4. FRONTEX (2012). Common integrated risk analysis model guidelines, v.2.0;

5. Regulation (EU) 2016/399 of the European Parliament and of the Council of 9 March 2016 on a Union Code on the rules governing the movement of persons across borders (Schengen Borders Code). 23.03.2016. Official Journal L, 2016, no. $77 / 1$.

6. Regulation (EU) 2019/1896 of the European Parliament and of the Council of 13 November 2019 on the European Border and Coast Guard and repealing Regulations (EU) No 1052/2013 and (EU) 2016/1624. 14.11.2019. Official Journal $L, 2019$, no. 295/1. 